\title{
Influence of fibre reinforced polymers in the rehabilitation of damaged masonry wallettes
}

\author{
Júnia Soares Nogueira Chagas ${ }^{*}$ and Gray Farias Moita
}

\author{
* Correspondence: \\ juniasnc@civil.cefetmg.br \\ Centro Federal de Educação \\ Tecnológica de Minas Gerais, Av. \\ Amazonas 7675, Nova Gameleira, \\ 30510-000 Belo Horizonte, MG, \\ Brazil
}

\begin{abstract}
In the past decade, the interest in repair and retrofitting of existing structures and rehabilitation of the damaged structures has led to the development of more effective and low invasive architectural and engineering strategies. In this aspect, the application of fibre reinforced polymer (FRP) strengthening techniques has become reasonably widespread as suitable solutions in addition to the traditional ones. They are promising techniques because of their key characteristics such as: high specific strength, high stiffness, small thickness compared to conventional materials, low influence on the global mass, little durability concerns, ease of handling, flexibility and fast installation that improve on-site productivity, and have a low impact on building functions. In this context, the use of carbon fibre reinforced polymers (CFRP) and glass fibre reinforced polymers (GFRP) for the rehabilitation of damaged small masonry walls (here called wallettes) was investigated experimentally. This study sought to measure the maximum loading carrying capacity of the wallettes and to assess the possible structural rehabilitation in the damaged masonry structures after their reinforcement with the composite polymers. For the adhesion between the wallettes and the reinforcement fibres, primer, putty and a saturant glue epoxy resins were used. Debonding between the FRP composites and the substrate has been recognized as the primary failure mechanism of this reinforcement system and it occurs when the system shear capacity is reached and the FRP is detached from the element. This phenomenon is also addressed in this paper. In general, the experimental results showed the recovery of the original compressive loading bearing capacity of the structures, in spite of the debonding of the FRP composites. Moreover, it could be observed an increasing of up to $39 \%$ and up to $49 \%$ of the compressive strength for the damaged masonry wallettes reinforced with CFRP and GFRP systems, respectively. The recover (or even rise) in the loading capacity of the reinforced structures due to the external fibres bonding is a good indication of their effectiveness in these situations.
\end{abstract}

Keywords: Rehabilitation; CFRP; GFRP; Masonry; Damage

\section{Springer}

\section{Background}

The structural masonry is a well-established traditional technology for the construction of affordable buildings. It is widely used throughout the world. Nowadays, simplicity and rationalisation of the construction process, aesthetic correctness, durability, low costs, good thermal and acoustic performance and fire resistance, among others, are characteristics that turn the masonry structures construction system into one of the most economical technology readily available [1]. In Brazil, structural masonry has been extensively used in the construction of the inexpensive buildings since the early 
1960's and, up to now, represents one of the promising solutions for the housing deficit in the country.

Nonetheless, problems with structural pathologies, failures and collapses have been reported. They are the result of the lack of more rigorous quality control for the materials and inadequate production processes. In some cases, these problems also occur due to the application of inaccurate empirical dimensioning methods, without the wide use of computational tools, which would yield a more accurate structural analysis results. In addition to these factors, others contribute to aggravate these problems, such as: the application of unpredicted loads, due to different uses and architectural modifications of the structure; foundation settlement; wrong structural conception; natural deterioration of the materials and components; and, impacts, collisions or explosions. In such situations, the reinforcement or rehabilitation of the damaged existing structures have been, often, more attractive or desirable than replacing it with a new construction due to heritage, economic and environmental reasons [2].

The adoption of low invasive and high efficient strengthening techniques is one important aspect for the success and viability of the rehabilitation interventions. With this in mind, the usage of fibre reinforced polymers (FRP) to enhance the structural performance of masonry structures is a promising technique because of its high specific strength, high stiffness and small thickness compared to the conventional materials [3].

In the literature, numerous studies on the strengthening of reinforced concrete structures with externally bonded FRP sheets have been published for many years. However, only more recently, experimental and numerical researches have been conducted about the usage of the FRP for the structural rehabilitation and strengthening of masonry walls. Very good results have been reported, what contribute to the success on this approach [4-7]. Nonetheless, only few contributions refer to aspects concerning to the bonding and debonding behaviour between the masonry elements and the strengthening system.

The effectiveness of the reinforcement and the failure behaviour of fibre reinforced masonry structures are strongly influenced by the properties of the substrate where the reinforcement is applied. Therefore, this factor requires to be further explored. In fact, the stress concentrations occurring at the FRP/substrate interface could lead to the detachment of the reinforcement from the support and to the premature failure of the structure due to debonding [8]. The bonding behaviour of the FRP reinforcements on masonry surface has been investigated and theoretical formulations have been suggested by a specific Italian guide document, which are derived from the approach for concrete structures [9].

More recently, specific experimental tests were developed to investigate the nature of the bonding between composite reinforcements and masonry substrates. Moreover, the mechanism of debonding has been studied considering the influence of various factors, such as, bond length, geometry of the specimen, tests set-up, and type of the fibre reinforcing system. It also can be observed that the wide variety of the masonry substrates, formed by clay or concrete bricks (or blocks), affects the overall performance of the reinforcement system [10-14].

In this work, a set of small masonry walls was built using concrete blocks. Three specimens, considered as the reference ones, were subjected to axial compressive loading up to their collapse in order to induce damage to the wallettes. Seven other 
specimens were submitted to axial compressive loading of $75 \%$ of the average collapse loading of the reference wallettes. As far as the mechanical behaviour is concerned, masonry structures subjected to a loading of $75 \%$ of their failure threshold is considered to be completely (structurally) damaged, which can be characterised by the appearance of randomly distributed cracks or micro-cracks throughout the specimens.

The damaged specimens were then prepared and strengthened by the application of carbon fibre reinforced polymers (CFRP) or glass fibre reinforced polymers (GFRP), completely covering both their two main surfaces, as shown in Figure 1. An adequate chemical and physical bonding between the polymeric fibre and the substrate of the masonry was utilized. After the application of the reinforcement system, the wallettes were once again subjected to a vertical compressive load up to their collapse. This study measured the maximum loading bearing capacity of the wallettes and assessed the possible structural rehabilitation in the damaged masonry structures after the reinforcement with the FRP.

\section{Methods}

\section{Materials characterisation and preparation of the specimens}

The masonry wallettes used in this research were built using concrete blocks and 1:2:6 (cement: hydrated lime: sand) mortar and had the following dimensions: height = $100 \mathrm{~cm}$; length $=80 \mathrm{~cm}$; thickness $=14 \mathrm{~cm}$, as shown in Figure 1 . Two different block sizes were utilised to build of the wallettes: (a) single-hole blocks (dimensions: $14 \mathrm{~cm} \mathrm{x}$

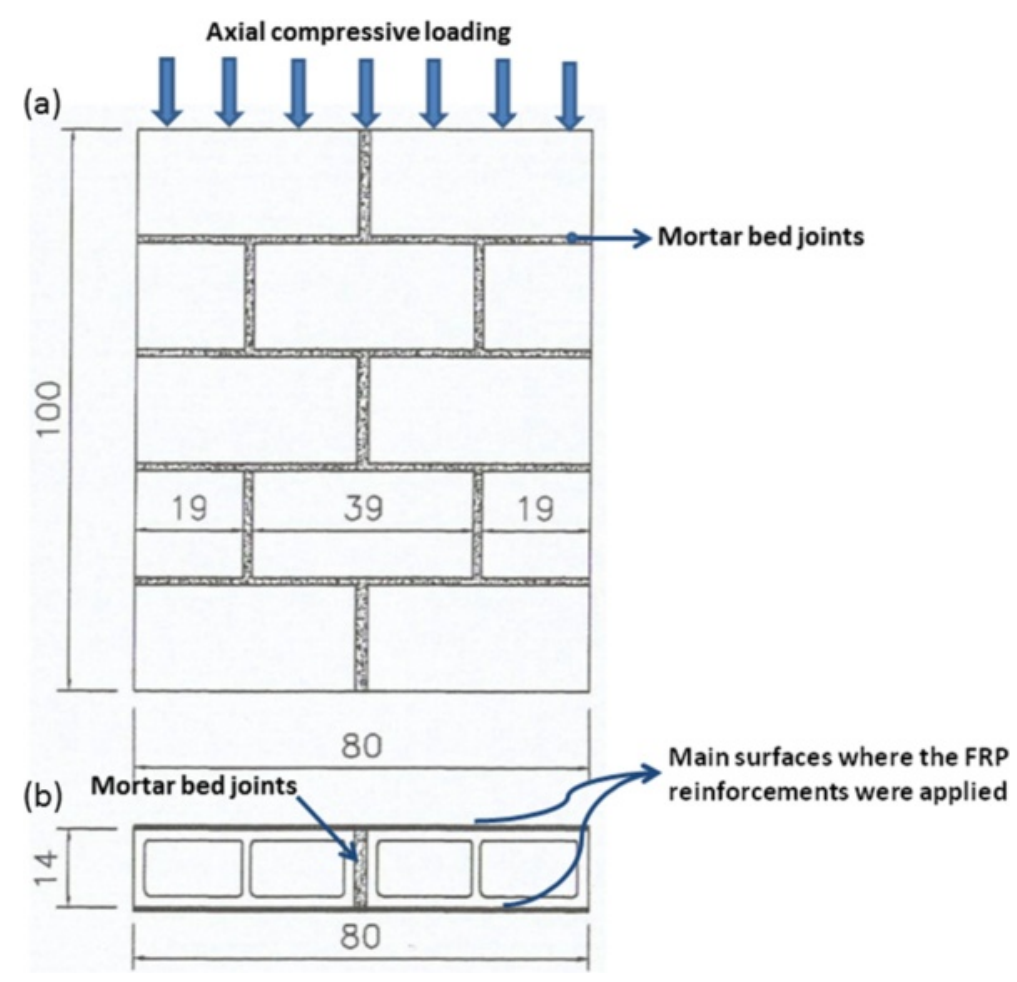

Figure 1 Geometric configuration of the wallettes, with the applied compressive loading. (a) frontal view and (b) top view, with indication of the FRP reinforcement. Dimensions in centimetres. 
$19 \mathrm{~cm} \mathrm{x} 19 \mathrm{~cm}$ ), and (b) two-hole blocks (dimensions: $14 \mathrm{~cm}$ x $19 \mathrm{~cm}$ x $39 \mathrm{~cm}$ ), depicted in Figure 2, in order to allow the desired geometric configuration of the panels. Their average compressive strengths were, respectively, $6.30 \mathrm{MPa}$ and 5.64 MPa. The mean compressive strength for the mortar specimens was $6.49 \mathrm{MPa}$. The experiments for the characterisation of the mechanical properties of these materials were conducted according to the Brazilian standards NBR 12118/2013 [15] and $13279 / 2005$ [16], respectively.

Three specimens of the walletes, namely RW1, RW2 and RW3, were built as schematic illustrated in Figure 1. Subsequently, they were subjected to axial compressive loading up to failure, which meant a mean load of $427 \mathrm{kN}$. The load was applied perpendicularly to the bed joints, in increments of the $2 \mathrm{kN}$, in an universal testing machine under vertical displacement control. During the loading, the strains along the loading axis were calculated using the average displacement measurements obtained from four dial gauges placed in the panels, two in each of the main sides. The test setup was established in accordance with the Brazilian standard NBR 15961-2/2011 [17]. These samples were considered the reference wallettes.

In order to cause damage to the wallettes, the seven remaining specimens were submitted to axial compressive loading of $75 \%$ of the average collapse loading of the reference wallettes, which resulted in a load of $320 \mathrm{kN}$. The loading was applied in the same direction as above. The applied loading was big enough to damage the specimens, as desired. From the visual inspection, micro-cracks and cracks could be observed in the blocks and the mortar joints of the structure, i.e., the wallettes were in fact damaged.

\section{Characteristics and mechanical properties of the resins and fibre reinforcement polymers}

The reinforcement system was made of polymeric fibre (FRP) and resins. The main mechanical properties of the FRP used in this work, given by the producer [18], were: for the CFRP (one-directional fabric mesh), Young's modulus E $=227 \mathrm{GPa}$ and tensile strength $\mathrm{f}_{\mathrm{t}}=3800 \mathrm{MPa}$; and, for the GFRP (two-directional fabric mesh), $\mathrm{E}=68.9 \mathrm{GPa}$, and $\mathrm{f}_{\mathrm{t}}=1517 \mathrm{MPa}$. Epoxy resins provided the bonding for the reinforcement system. The resins used were a primer, a saturant and a leveling compound called putty. They

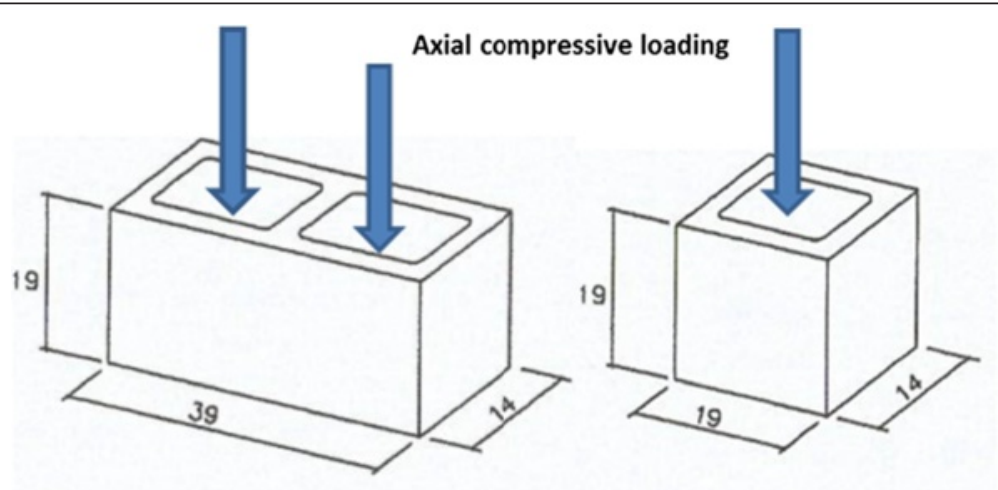

Figure 2 Concrete blocks used, with the axial compressive loading applied during testing (according to NBR 12118/2013). Dimensions in centimetres. 
are all two-component materials consisting of resin and hardener. Their main characteristics and mechanical properties are given in Tables 1,2,3.

\section{Preparation of the masonry substrate and application of the reinforcement}

Before the application of the fibre reinforcement, the wallettes were prepared using high pressure water blasting in order remove the powder and any other particles from the substrate. They were dried in room temperature for 7 days. Subsequently, the damaged specimens were strengthened by the application of one-directional fabric of CFRP. These wallettes were denominated CW1, CW2, and CW3. The specimens GW1, GW2, GW3 and GW4 received two-directional fabric of GFRP. The FRP layers covered both the two main surfaces of all damaged specimens, according to Figure 1.

An adequate chemical and physical bonding between the FRP and the substrate of the masonry was established. Firstly, the substrate of the wallettes was prepared with the application one layer of the primer. This primer is a two-component solvent-less epoxy system which when mixed yields a penetrating medium viscosity compound. This primer is used to penetrate the pore structure of the cementitious substrates and to provide a high bonding base coating for the FRP system. The drying of the primer on the substrate took around 1 hour in room temperature. Figure 3 illustrates the primer application. Since the damaged wallettes did not present crushed parts, only cracks or micro-cracks, there was no need to fill the collapsed regions with mortar.

Within a 48-hour period after the drying of the primer, a second layer of the adhesion system was applied, with a thickness of around $2 \mathrm{~mm}$. This epoxy resin is known as putty. It was useful for the regularisation of any small surface imperfections and to provide a smooth surface to which the reinforcement system would be applied. The drying/hardening of the putty is an exothermic process that lasts around an hour. Figure 4 depicts the substrate regularisation when the putty was used.

The system was glued with a resin denominated saturant applied in two coatings, again within a 48-hour period to ensure the proper adhesion. This saturant is epoxy based, solvent free, high strength adhesive. One layer is applied over the primer, or the putty, already dried. At around one hour, before the saturant became tacky, the FRP fabric was applied. Within 2 hours, a second layer of saturant was applied on top of the FRP (Figure 5). Finally, a roller was used to expel any bubbles (Figure 6). The whole cure process took 7 days in room temperature, ranging between 25 to $35^{\circ} \mathrm{C}$.

Table 1 Characteristics and mechanical properties of the primer

\begin{tabular}{llll}
\hline Properties & Compressive & Tensile & Flexural \\
\hline Yield strength & $26.2 \mathrm{MPa}$ & $14.5 \mathrm{MPa}$ & $24.1 \mathrm{MPa}$ \\
Strain at yield & $4.0 \%$ & $2.0 \%$ & $4.0 \%$ \\
Elastic modulus & $670 \mathrm{MPa}$ & $717 \mathrm{MPa}$ & $595 \mathrm{MPa}$ \\
Ultimate strength & $28.3 \mathrm{MPa}$ & $17.2 \mathrm{MPa}$ & $24.1 \mathrm{MPa}$ \\
Rupture strain & $10 \%$ & $40 \%$ & Large deformation with no rupture \\
Poisson's ratio & - & 0.48 & \\
Pot life & 40 min at $25^{\circ} \mathrm{C}$ & & \\
Cure & Fully cured at $20^{\circ} \mathrm{C}-7$ days & \\
\hline
\end{tabular}


Table 2 Characteristics and mechanical properties of the putty

\begin{tabular}{llll}
\hline Properties & \multicolumn{1}{c}{ Compressive } & Tensile & Flexural \\
\hline Yield strength & $22.8 \mathrm{MPa}$ & $12.0 \mathrm{MPa}$ & $26.2 \mathrm{MPa}$ \\
Strain at yield & $4.0 \%$ & $1.5 \%$ & $4.0 \%$ \\
Elastic modulus & $1076 \mathrm{MPa}$ & $1800 \mathrm{MPa}$ & $895 \mathrm{MPa}$ \\
Ultimate strength & $22.8 \mathrm{MPa}$ & $15.2 \mathrm{MPa}$ & $27.6 \mathrm{MPa}$ \\
Rupture strain & $10 \%$ & $7 \%$ & $7 \%$ \\
Poisson's ratio & - & 0.48 & - \\
Pot life & 40 min at $25^{\circ} \mathrm{C}$ & & \\
Cure & Fully cured at $20^{\circ} \mathrm{C}-7$ days & & \\
\hline
\end{tabular}

The wallettes GW1, GW2, CW2 and CW3 were treated with the putty regularisation. The remaining walls, CW1, GW3 and GW4, did not receive the putty treatment.

The main direction of the fibre was positioned horizontally in the walls, that is, in the direction perpendicular to the axial loading application. This configuration was chosen so that a more effecting enveloping (or confining effect) in the damaged structures could be obtained. The enveloping mentioned above can be understood as the wrapping effect on the wallettes, based upon the hypothesis that the thickness of the walls is much smaller than the FRP covered surfaces. As a result of such a configuration, an increase in the compressive strength and the shear capacity of the structures was expected.

\section{Axial compressive loading experiments}

After the application of the reinforcement system onto the damaged wallettes, they were again subjected to a vertical compressive loading, up to their collapse. In this second loading, the relative vertical displacement was measured until the total load reached approximately $250 \mathrm{kN}$, which was around $60 \%$ of the reference collapse load. This procedure prevented damage in the measurement equipment if a sudden structural fail should occur. The experiments were performed in accordance with the Brazilian standard NBR15961-2/2011 [17]. For comparison with the reference wallettes experimental results, the Young's modulus was also determined for these reinforced wallettes.

Table 3 Characteristics and mechanical properties of the saturant

\begin{tabular}{|c|c|c|c|}
\hline \multicolumn{4}{|l|}{ Properties } \\
\hline & Compressive & Tensile & Flexural \\
\hline Yield strength & $86.2 \mathrm{MPa}$ & $54.0 \mathrm{MPa}$ & $138.0 \mathrm{MPa}$ \\
\hline Strain at yield & $5.0 \%$ & $2.5 \%$ & $3.8 \%$ \\
\hline Elastic modulus & $2620 \mathrm{MPa}$ & $3034 \mathrm{MPa}$ & $3724 \mathrm{MPa}$ \\
\hline Ultimate strength & $86.2 \mathrm{MPa}$ & $55.2 \mathrm{MPa}$ & $138.0 \mathrm{MPa}$ \\
\hline Rupture strain & $5.0 \%$ & $3.5 \%$ & $5 \%$ \\
\hline Poisson's ratio & - & 0.40 & _- \\
\hline Pot life & \multicolumn{3}{|l|}{$45 \mathrm{~min}$ at $25^{\circ} \mathrm{C}$} \\
\hline Cure & \multicolumn{3}{|c|}{ Fully cured at $20^{\circ} \mathrm{C}-7$ days } \\
\hline
\end{tabular}




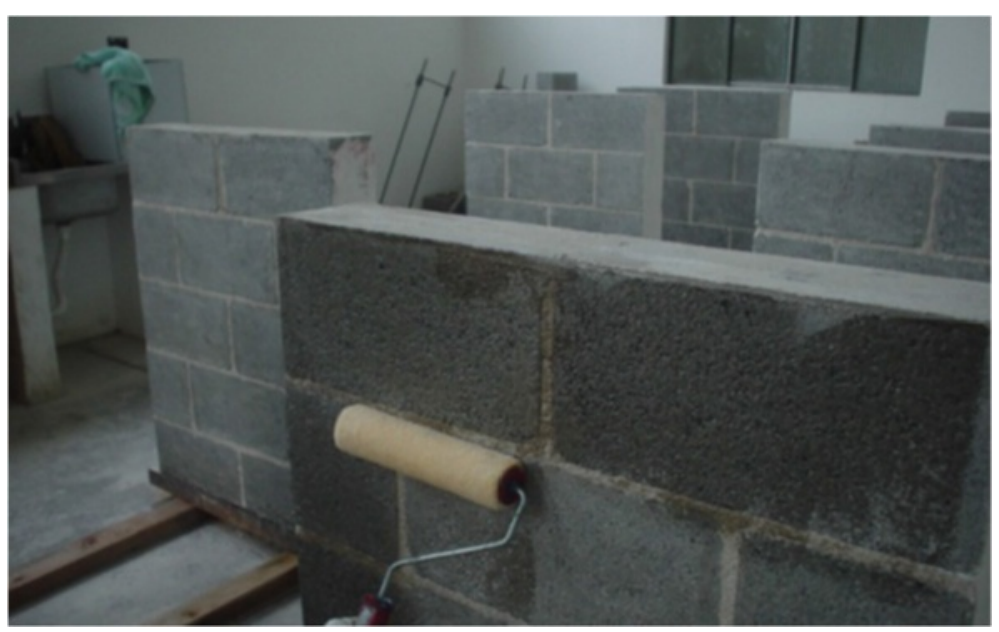

Figure 3 Application of the primer on the damaged wallettes.

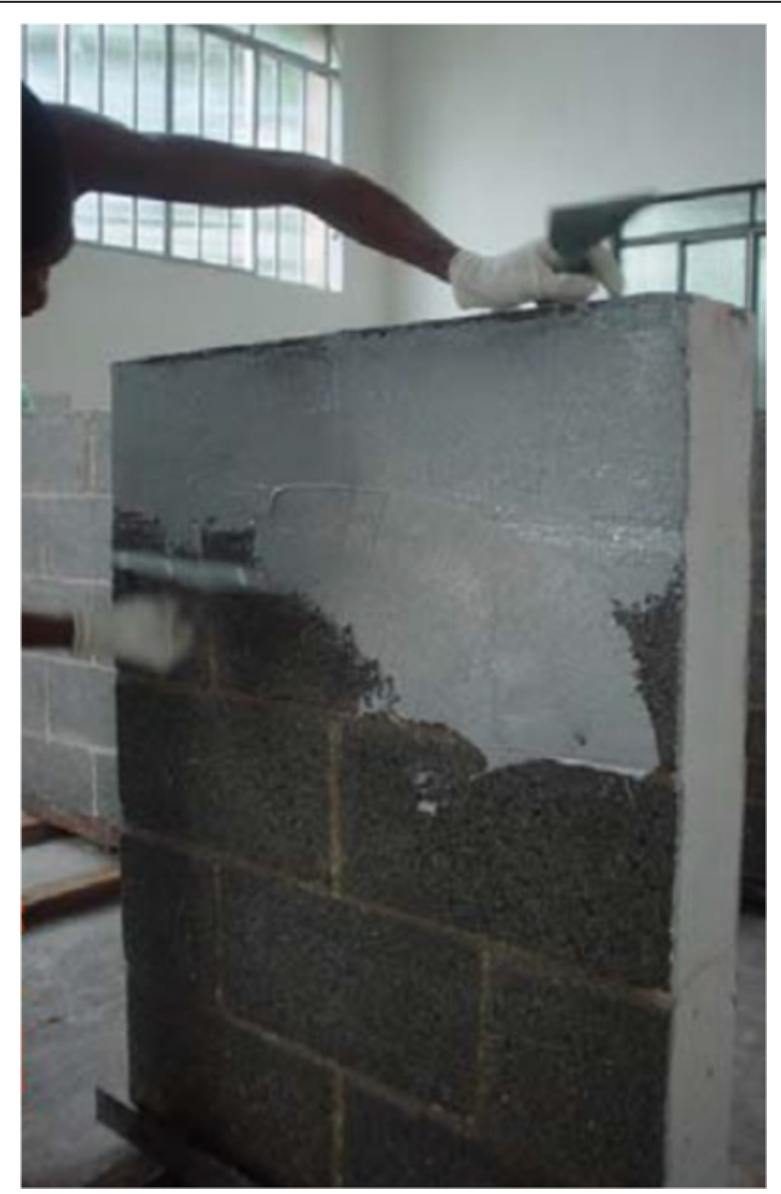

Figure 4 Putty application. 

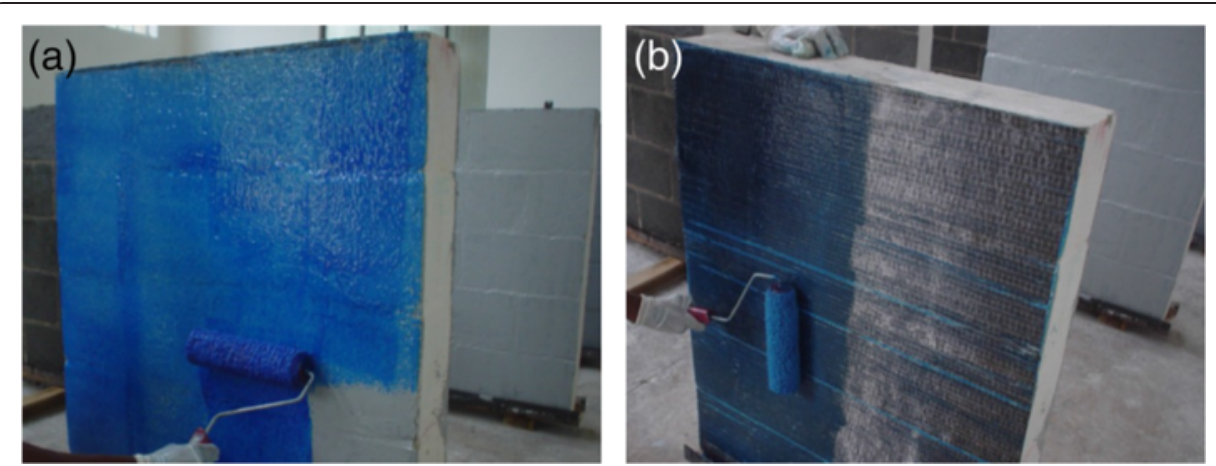

Figure 5 Application of the saturant resin: (a) first layer and (b) second layer on top of the FRP.

\section{Results and discussion}

\section{Axial compression results}

The results of the experiments of specimens RW1, RW2 and RW3 under compression are shown in Table 4.

Tables 5 and 6 present the efficiency obtained in the compressive strength for each of the applied reinforcement systems when compared to the reference wallettes. It can be noted, in general, that all the tested specimens were able to recover the original strength (and even achieving higher values).

It can be seen from the tables that the specimens reinforced with CFRP that received the putty (CW2 and CW3) presented a much better performance in relation to mechanical resistance as compared to the wallette that was not prepared with the putty (CW1). The overall compressive strength gain was up to $39 \%$ for CW2 and CW3, whereas CW1 achieved roughly the reference strength, with a small $4 \%$ increase. On the other hand, the wallettes reinforced with GFRP presented non-uniform results, which does not allow for a definitive conclusion over their mechanical behaviour: the wallettes treated with putty presented a compressive strength increasing of $5 \%$ and $21 \%$, while those that did not received the putty presented a strength improvement of $17 \%$ and $49 \%$, as shown in Table 6.

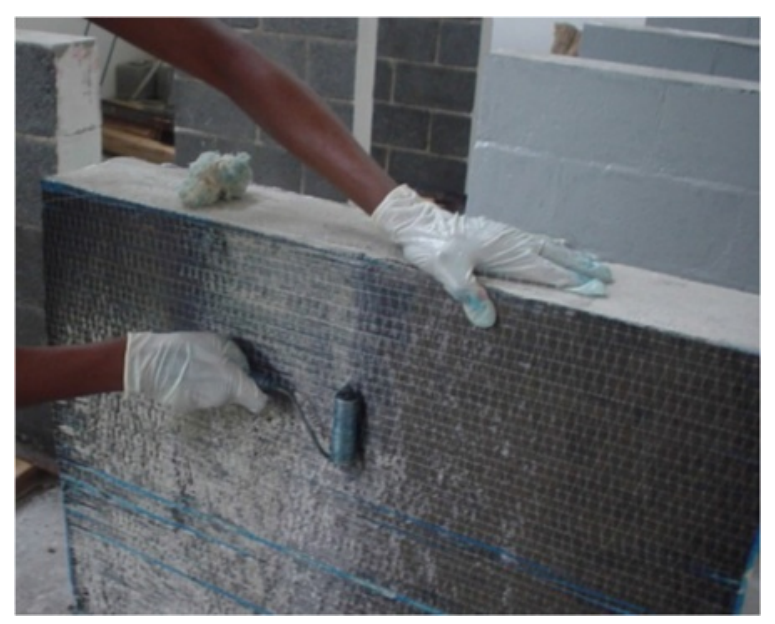

Figure 6 Roller used to expel bubbles. 
Table 4 Compressive strength of the reference wallettes

\begin{tabular}{lllll}
\hline Wallettes & $\begin{array}{l}\text { Compressive strength } \\
\text { [MPa] }\end{array}$ & $\begin{array}{l}\text { Average compressive } \\
\text { strength [MPa] }\end{array}$ & $\begin{array}{l}\text { Standard } \\
\text { deviation }\end{array}$ & $\begin{array}{l}\text { Variation coefficient } \\
{[\%]}\end{array}$ \\
\hline RW1 & 3.93 & 3.82 & 0.10 & 2.64 \\
RW2 & 3.75 & & & \\
RW3 & 3.79 & & & \\
\hline
\end{tabular}

According to the manufacturers, the use of a proper adhesive system does not confer any extra mechanical strength to the FRP composite, but the adhesive is capable of creating a link between the substrate and FRP system and is able to distribute the applied loads. The above results confirm that the bonding between the FRP external reinforcement and the substrate is one of the key issues for the recovery of load capacity for reinforced structures $[9,14]$.

\section{Young's modulus and stress-strain behaviour}

The Young's modulus was also determined for the reinforced wallettes and a comparison with the reference specimens was made. The results indicated that the reference (before reinforcement) and the FRP reinforced (after reinforcement) wallettes presented very similar behaviour under the compressive loading, as shown in Tables 7 and 8 . These results suggest that the stiffness of the wallettes was also recovered after the application of the FRP reinforcement.

With regard to the stress-strain behaviour, the performance of the wallettes reinforced with CFRP was very similar when compared with their GFRP counterpart. Besides, both reinforcement systems presented stress-strain curves comparable to the curve for the undamaged specimens (before receiving the reinforcement), as depicted in Figures 7 and 8, indicating the rehabilitation of the strengthened structures.

\section{Failure mode}

From the experiments, it could be observed that a fragile, localised and sudden collapse occurred in the reference wallettes. In the majority of the cases, the cracks started when the loading approached its failure limit, i.e., approximately $75 \%$ of the estimated maximum load. This confirms the low ductility of the walls and the well-known expected fragile behaviour of the masonry structures [19].

Moreover, from the experiments in this study, it could be observed that the FRP reinforcement applied did not exhibit, during the entire loading process, faults or fracture of the adherent that could be visible to the naked eye. Figures 9 and 10 show that the CFRP reinforced wallettes that received the putty treatment (CW2 and CW3)

Table 5 Obtained efficiency of the wallettes reinforced with one-directional fabric of CFRP

\begin{tabular}{lllllll}
\hline Wallettes & Set up & $\begin{array}{l}\text { Achieved maximum } \\
\text { strength [MPa] }\end{array}$ & $\begin{array}{l}\text { Reference strength } \\
\text { [MPa] }\end{array}$ & Efficiency & $\begin{array}{l}\text { Standard } \\
\text { deviation }\end{array}$ & $\begin{array}{l}\text { Variation } \\
\text { coefficient [\%] }\end{array}$ \\
\hline CW1 & $\begin{array}{l}\text { Without } \\
\text { putty }\end{array}$ & 3.96 & 3.82 & 1.04 & 0.77 & 15.84 \\
& & & & & \\
CW2 & With putty & 5.27 & & 1.38 & & \\
CW3 & & 5.31 & & 1.39 & & \\
\hline
\end{tabular}


Table 6 Obtained efficiency of the wallettes reinforced with two-directional fabric of GFRP

\begin{tabular}{lllllll}
\hline Wallettes & Set up & $\begin{array}{l}\text { Achieved maximum } \\
\text { strength [MPa] }\end{array}$ & $\begin{array}{l}\text { Reference } \\
\text { strength [MPa] }\end{array}$ & Efficiency & $\begin{array}{l}\text { Standard } \\
\text { deviation }\end{array}$ & $\begin{array}{l}\text { Variation } \\
\text { coefficient [\%] }\end{array}$ \\
\hline GW1 & With putty & 4.02 & 3.82 & 1.05 & 0.72 & 15.28 \\
GW2 & & 4.62 & & 1.21 & & \\
GW3 & Without putty & 4.46 & & 1.17 & & \\
GW4 & & 5.71 & 1.49 & & \\
\hline
\end{tabular}

presented failure of the reinforcement system only after the total collapse of the structures, without presenting fibre debonding, neither between the FRP and the adhesive system, nor between the concrete substrate and the adhesive system. The failure mode of the specimen CW2 (Figure 9) suggests that the fibre reinforcement allowed for the structural masonry wallette to reach its maximum working loading capability, even after suffering the imposed damaging. Figure 10 brings the failure mode of the CW3 structure, where the fragile rupture of the concrete blocks can be seen. Here, again, no debonding between the substrate and the adhesive or between the adhesive and the FRP can be observed. This fact, combined with the maximum loading bearing capacity shown by the CW2 and CW3 specimens (as in Table 5), implies that the application of the putty contributes to the rehabilitation, as well as to the increase of the loading bearing capacity, as the result of a better bonding of the reinforcement system to the substrate. However, the CW1 specimen (Figure 11) that did not receive the putty treatment offered a premature failure when compared with the specimens CW2 and CW3, as shown in Table 5. From this figure, it is possible to observe the debonding of the reinforcement fibres, when the wallette reached its original failure loading, i.e., the lack of bonding of the FRP limited its performance and it only displayed a small loading capacity improvement.

The experimental results confirmed, in general, the recovery of the original compressive loading bearing capacity of the structures. Moreover, it could be seen an increasing of up to $39 \%$ and up to $49 \%$ of the compressive strength for the damaged masonry wallettes reinforced with CFRP and GFRP systems, respectively, as shown in Tables 5 and 6.

The ultimate load attainable by FRP reinforcement depends essentially upon the compressive and tensile strengths of the substrate. Debonding between the FRP composite and the substrate has been recognised as the principal failure mechanism of the reinforcement system. Debonding occurs when the system shear capacity is reached and the FRP reinforcement is detached from the element. Since the substrate is usually weaker than the glue and the reinforcement, failure is normally associated with the

Table 7 Initial tangential Young's modulus for the wallettes reinforced with CFRP

\begin{tabular}{|c|c|c|c|c|c|c|c|}
\hline \multirow[b]{2}{*}{ Wallettes } & \multirow[b]{2}{*}{ Set up } & \multicolumn{3}{|c|}{ Before of the reinforcement } & \multicolumn{3}{|c|}{ After the reinforcement } \\
\hline & & $\overline{E(M P a)}$ & $\begin{array}{l}\text { Average value } \\
(\mathrm{MPa})\end{array}$ & $\begin{array}{l}\text { Variation } \\
\text { coefficient (\%) }\end{array}$ & $\begin{array}{l}E \\
(M P a)\end{array}$ & $\begin{array}{l}\text { Average } \\
\text { value (MPa) }\end{array}$ & $\begin{array}{l}\text { Variation } \\
\text { coefficient (\%) }\end{array}$ \\
\hline CW1 & $\begin{array}{l}\text { Without } \\
\text { putty }\end{array}$ & 5869 & 6100 & 8.50 & 5625 & 6170 & 8.38 \\
\hline CW2 & With putty & 6110 & & & 6653 & & \\
\hline CW3 & & 6320 & & & 6233 & & \\
\hline
\end{tabular}


Table 8 Initial tangential Young's modulus for the wallettes reinforced with GFRP

\begin{tabular}{|c|c|c|c|c|c|c|c|}
\hline \multirow[b]{2}{*}{ Wallettes } & \multirow[b]{2}{*}{ Set up } & \multicolumn{3}{|c|}{ Before of the reinforcement } & \multicolumn{3}{|c|}{ After the reinforcement } \\
\hline & & $E(M P a)$ & $\begin{array}{l}\text { Average value } \\
(\mathrm{MPa})\end{array}$ & $\begin{array}{l}\text { Variation } \\
\text { coefficient (\%) }\end{array}$ & $E(M P a)$ & $\begin{array}{l}\text { Average } \\
\text { value (MPa) }\end{array}$ & $\begin{array}{l}\text { Variation } \\
\text { coefficient (\%) }\end{array}$ \\
\hline GW1 & \multirow{2}{*}{ With putty } & 5890 & \multirow[t]{4}{*}{7050} & \multirow[t]{4}{*}{12.09} & 6117 & \multirow[t]{4}{*}{6837} & \multirow[t]{4}{*}{9.81} \\
\hline GW2 & & 7078 & & & 6821 & & \\
\hline GW3 & \multirow{2}{*}{ Without putty } & 7927 & & & 6676 & & \\
\hline GW4 & & 7306 & & & 7734 & & \\
\hline
\end{tabular}

removal of a material layer during debonding. These behaviours have been widely studied for applications to concrete columns and beams, both from the experimental and numerical points of view, but, as far as masonry is concerned, only a limited number of studies can be found in literature [20]. In the current investigation, this fact can be observed and confirmed (see Figure 11).

In addition, it is believed that an "enveloping effect" was obtained with the FRP reinforcement. Also, the small confining action on the wallettes and, especially, the maintenance of the original geometry of the specimens were observed. These factors were considered responsible for the rehabilitation of the bearing capacity of the structures under the applied vertical compressive loads. The reinforcement application, and its potential of avoiding new cracks opening and the growth of the existing cracks, was also important to the final rehabilitation of masonry walls.

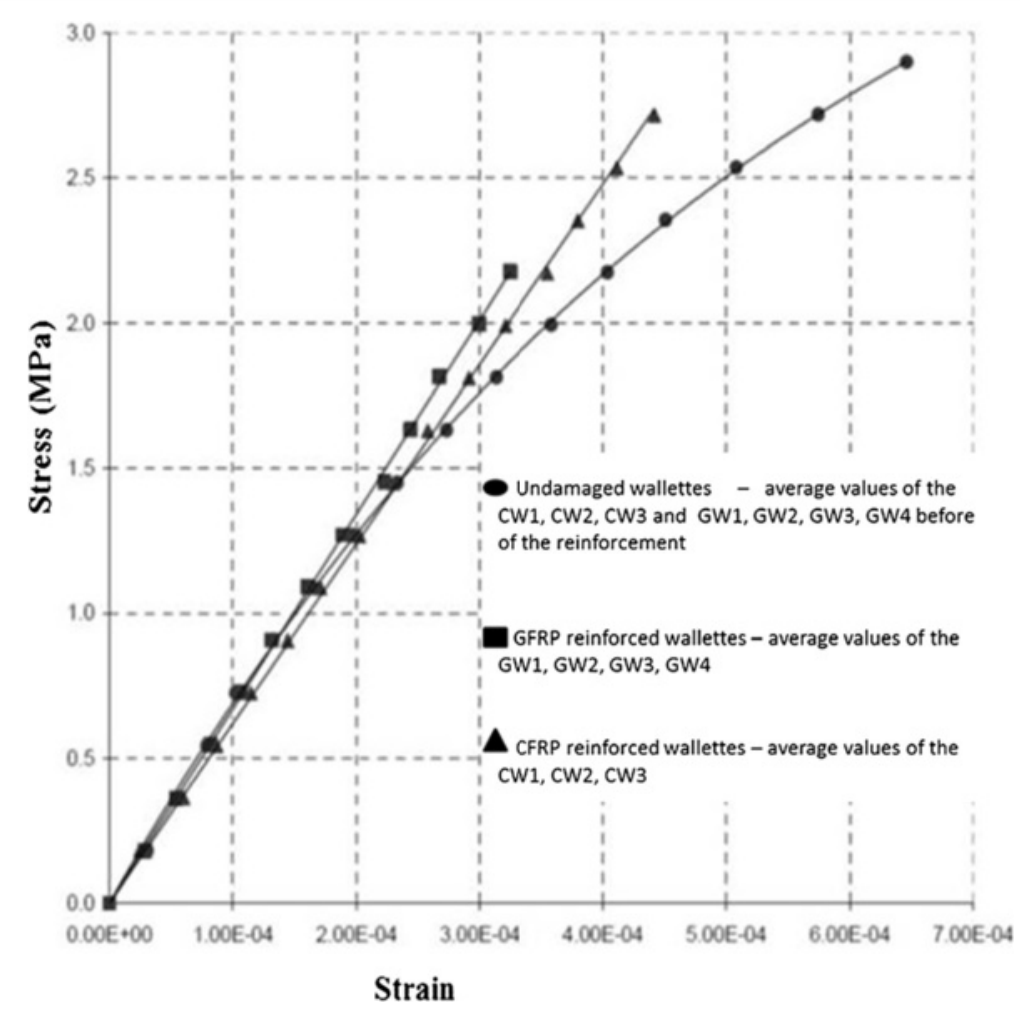

Figure 7 Mean values for stress-strain curves of the wallettes behaviour before and after the FRP reinforcement. 


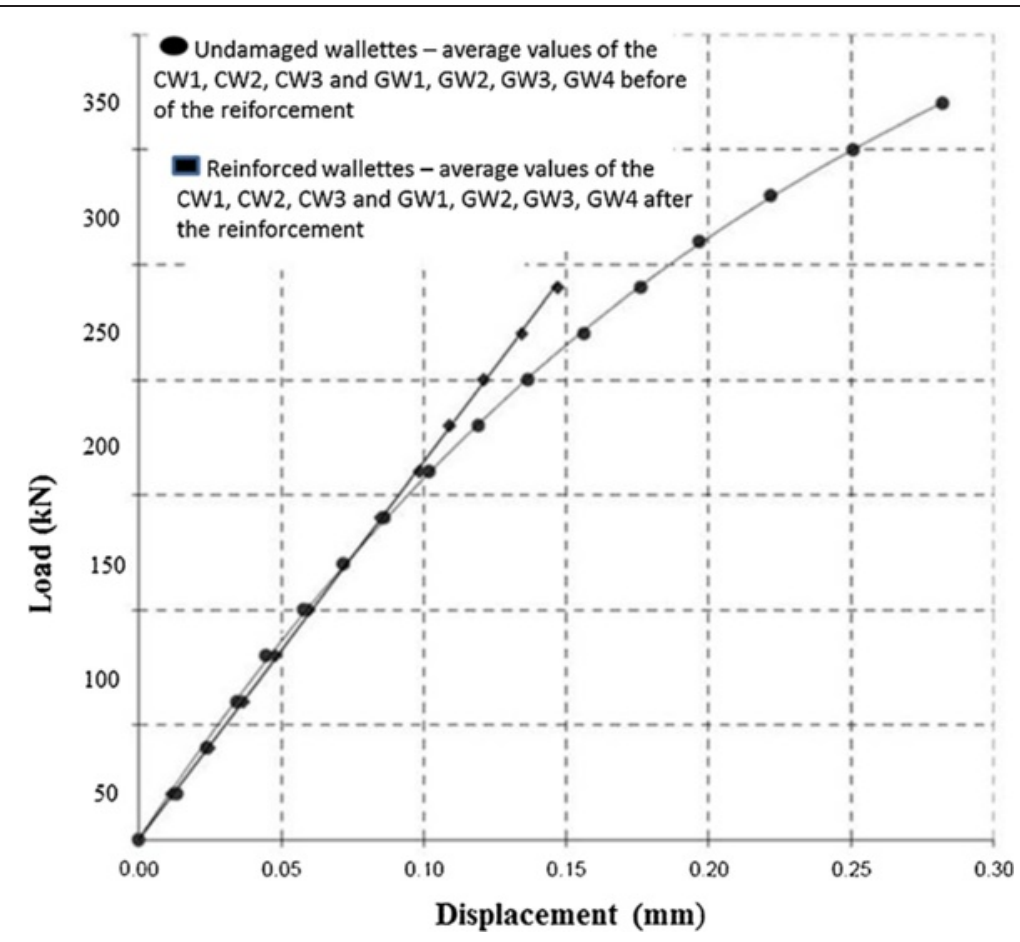

Figure 8 Mean values for the load-displacement curves of the wallettes behaviour before and after the FRP reinforcement.
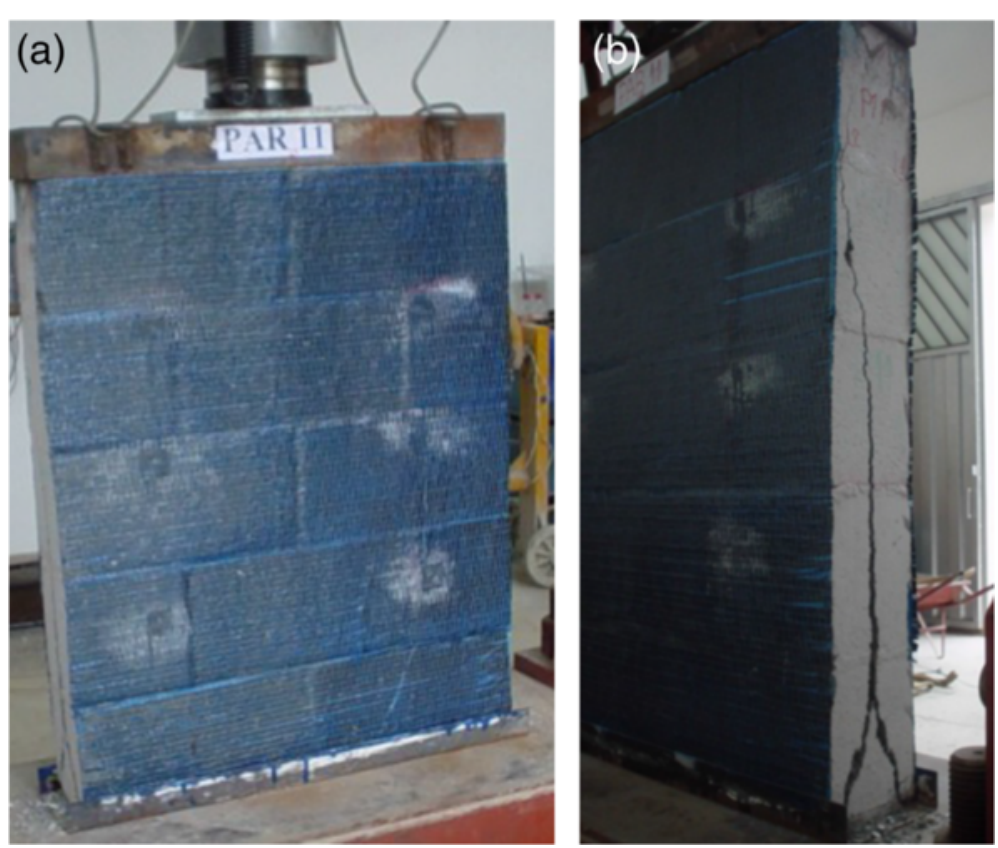

Figure 9 Failure of the CW2 wallette reinforced with CFRP (with putty). (a) Frontal view and (b) lateral view. 


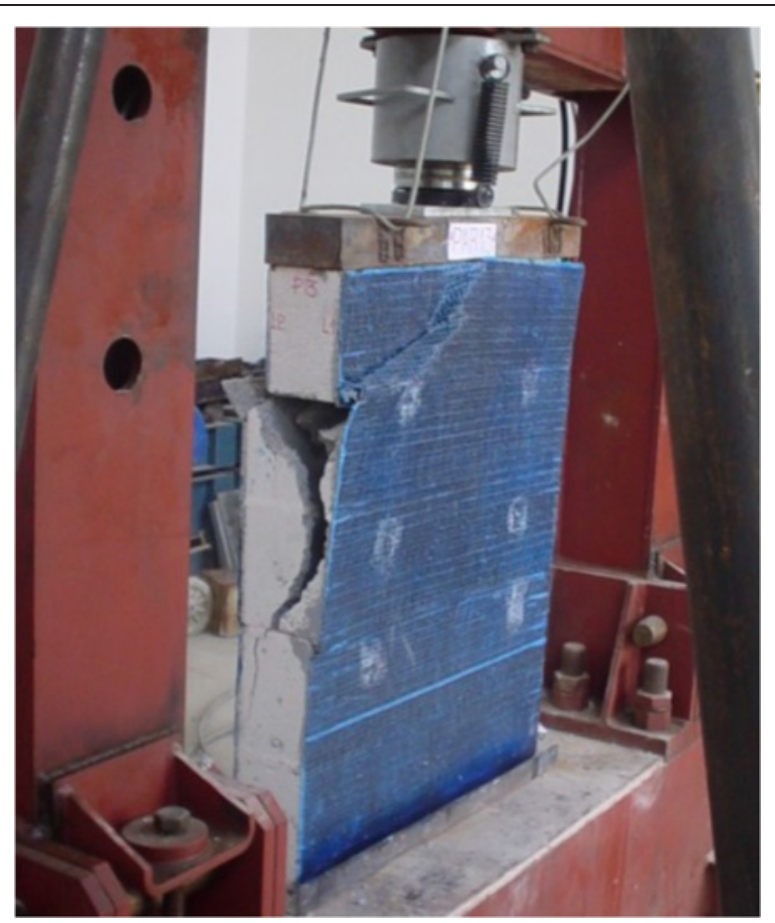

Figure 10 Failure of the CW3 wallette reinforced with CFRP (with putty).

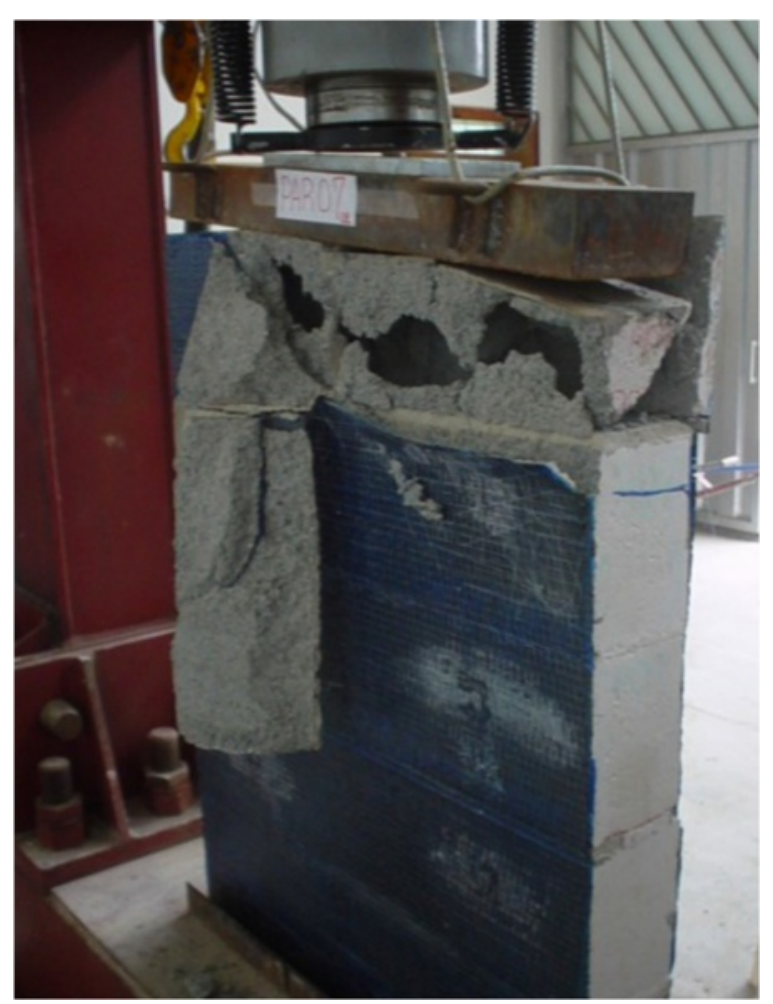

Figure 11 Failure of the CW1 wallette reinforced with CFRP (without putty). 
Finally, it is relevant to comment that the long-term durability of the reinforced structures was not addressed in the current research.

\section{Conclusions}

The main objective of this work was to present the rehabilitation potential offered by the CFRP and GFRP applied over previously damaged masonry wallettes. The wallettes were tested under axial compressive loading, before and after the application of the FRP reinforcement. It could be noted that the damaged, and later rehabilitated, wallettes could stand the maximum reference loading, with gains of $4 \%$ to $49 \%$ on the compressive strength in comparison with the measured failure loading of the undamaged reference wallettes. Both CFRP and GFRP reinforced wallettes showed loaddisplacement and stress-strain curves similar to those obtained from the reference wallettes. Debonding between the FRP composite and the substrate can be attributed as premature failure of the reinforcement system and, consequently, of the reinforced wallettes, as observed here. Moreover, the small confining action and the maintenance of the geometry contributed for rehabilitation of the damaged wallettes.

The increase in the load carrying capacity of the reinforced structures due to the external fibres bonding is a good indication of their effectiveness in these situations. Hence, the obtained results point out the potential and applicability of the FRP reinforcement system technique in full-scale problems for masonry structures.

Competing interests

The authors declare that they have no competing interests.

\section{Authors' contributions}

JSCN and GFM prepared the samples, ran the experiments and wrote the paper. Both authors read and approved the final manuscript.

\section{Acknowledgments}

The authors would like to acknowledge CEFET-MG for their support during the course of this work.

Received: 19 November 2014 Accepted: 16 February 2015

Published online: 15 March 2015

\section{References}

1. Hendry AW (2002) Engineered design of masonry buildings: fifty years development in Europe. Prog Structur Engineer Mater 4:291-300

2. Asteris PG, Giannopoulos IP (2012) Vulnerability and restoration assessment of masonry structural systems. Electron J Struct Eng 12:82-93

3. Hollaway LC, Head PR (2001) Advanced polymer composites and polymers in the civil infrastructure, 1st edn. Elsevier: Netherlands; pp 109-155

4. Masia MJ, Shrive NG (2003) Carbon fibre reinforced polymer wrapping for the rehabilitation of masonry columns. Can J Civ Eng 30:734-744

5. Prakash SS, Alagusundaramoorthy P (2008) Load resistance of masonry wallettes and shear triplets retrofitted with GFRP composites. Cement Concrete Composites 30:745-761

6. Fedele R, Milani G (2010) A numerical insight into the response of masonry reinforced by FRP strips. The case of perfect adhesion. Compos Struct 92:2345-2357

7. Faella C, Camorani G, Martinelli E, Paciello SO, Perri F (2012) Bond behaviour of FRP strips glued on masonry: experimental investigation and empirical formulation. Constr Build Mater 31:353-363

8. Grande E, Imbimbo M, Sacco E (2011) Bond behaviour of CFRP laminates on clay bricks: experimental and numerical study. Compos Part B 42:330-340

9. CNR.CNR-DT200 (2006) Guide for the design and construction of externally bonded FRP systems for strengthening existing structures - materials, RC and PC structures, masonry structures. National Research Council, Rome-CNR, Roma, Italy

10. Benrahou KH, Adda bedia EA, Benyoucef S, Tounsi A, Benguediab M (2006) Interfacial stresses in damaged RC beams strengthened with externally bonded CFRP plate. Mater Sci Eng A 432:12-19

11. Aiello MA, Sciolti MS (2008) Analysis of bond performance between FRP sheets and calcarenite stones under service and ultimate condition. J Brit Masonry Soc Masonry Int 21:15-28

12. Mendola LL, Failla A, Cucchiara C, Accardi M (2009) Debonding phenomena in CFRP strengthened calcarenite masonry walls and vaults. Adv Struct Eng 12:745-760 
13. Willis CR, Yanga Q, Seracino R, Griffith MG (2009) Bond behaviour of FRP-to-clay brick masonry joints. Eng Struct 31:25802587

14. Carrara P, Ferretti D, Freddi F (2013) Debonding behavior of ancient masonry elements strengthened with CFRP sheets. Compos Part B 45:800-810

15. ABNT - Associação Brasileira de Normas Técnicas (2013) NBR 12118: Blocos vazados de concreto simples para alvenaria - Determinação da resistência à compressão. Método de Ensaio: Rio de Janeiro Associação Brasileira de Normas Técnicas.

16. ABNT - Associação Brasileira de Normas Técnicas (2005) NBR13279: Argamassa para assentamento e revestimento de paredes e tetos. Rio de Janeiro: Associação Brasileira de Normas Técnicas.

17. ABNT - Associação Brasileira de Normas Técnicas (2011) NBR 15961-2: Alvenaria estrutural - Blocos de concreto Parte 2: Execução e controle de obras. Rio de Janeiro Associação Brasileira de Normas Técnicas.

18. Basf, The Chemical Company. 2014. Master Builders Solutions - Technical Data Guide. http://www.master-builderssolutions.basf.us/en-us/products/masterbrace/1507. Accessed 12 October 2014

19. Andreaus U (1996) Failure criteria for masonry panels under in-plane loading. J Struct Eng 122:37-46

20. Oliveira DV, Lourenço PB (2011) Experimental bond behaviour of FRP sheets glued on brick masonry. J Compos Constr 11:319-327

Submit your manuscript to a SpringerOpen ${ }^{\circ}$ journal and benefit from:

- Convenient online submission

Rigorous peer review

- Immediate publication on acceptance

- Open access: articles freely available online

- High visibility within the field

Retaining the copyright to your article

Submit your next manuscript at $>$ springeropen.com 